\title{
THE IMPACT OF LANDSLIDE AREAS ON MUNICIPAL SPATIAL PLANNING*
}

\author{
Jarosław Bydłosz, PhD \\ Faculty of Mining Surveying and Environmental Engineering \\ AGH University of Science and Technology \\ e-mail:bydlosz@agh.edu.pl \\ Paweł Hanus, PhD \\ Faculty of Mining Surveying and Environmental Engineering \\ AGH University of Science and Technology \\ e-mail:phanus@agh.edu.pl
}

\begin{abstract}
Municipal spatial planning is one of the key elements of a national spatial policy and the local land use plan is the most important tool for shaping this policy. The local land use plan, as opposed to the study, is a provision of the local law. The study, however, is mandatory for the whole area of the municipality, while the local land use plan is, in principle, voluntary and subject to certain exceptions.

One of the elements which ought to be included in the spatial policy a municipality is taking into account the threats to the safety of its inhabitants and their property, as well as identifying areas of natural geological hazards. Therefore, both the study and the local land use plan of the municipality should include, among others, areas of particular risk related to the subsidence of soil masses, i.e., landslide areas. Landslide areas are of a limited use for investment purposes, including residential, industrial or service development, as particularly vulnerable to the phenomenon of rock masses, eluvium or sediments sliding down slopes under the force of gravity.

The purpose of this article is to analyze the legal and economic consequences resulting from changes to the local land use plan, related to the qualification of an area as a landslide area. This paper examines the changes to the local land use plan for the town of Wieliczka, located place on the border of the Outer Carpathians and the Carpathian Foredeep. The transition from a mountainous terrain into a plane gives rise to numerous natural forms of relief which are prone to landslides. The study of landslides in the municipality of Wieliczka conducted in 2008, resulted in changing the qualifications of many areas to areas at risk of soil subsidence. The effects of the study have been reflected in the new local land use plan introduced in 2010.
\end{abstract}

Keywords: local land use plan, spatial planning, landslides.

JEL Classification: Q54, Q58.

Citation: Bydłosz J., Hanus P., (2013), "The impact of landslide areas on municipal spatial planning", Real Estate Management and Valuation, vol. 21, no. 4, pp. 5-10.

DOI: $10.2478 /$ remav-2013-0031.

\section{Introduction}

Spatial planning is a key element of the sustainable development of every country. In Poland, a municipal land use plan plays a major role in this matter. The adopted plan, as a provision of the local

\footnotetext{
* This work is financed from funds for science no. 11.11.150.006, realized at AGH University of Science and Technology, allocated for the year 2013.
} 
law, is binding for inhabitants of a municipality along with other provisions of the law. Proper records of the plan allow the municipality and, in particular, its inhabitants to confidently and, above all, predictably develop space. The plan enables the inhabitants to check the direction in which the municipality is developing and, therefore, to adapt their own actions to the anticipated changes. Due to the costs and magnitude of work involved, changes to the plan are uncommon. The updates are usually only of a local character and respond to requests submitted by owners, as well as adapting the plan to the new requirements of the law.

One of the elements which is supposed to be included in the spatial policy of a municipality is taking into account threats to the safety of the inhabitants and their property, as well as identifying the areas of natural geological hazards. Therefore, the study of conditions and directions of spatial management includes, among others, areas of particular risk related to the subsidence of soil masses, i.e., landslide areas. The local land use plan, related to the study of the municipality, should also define the boundaries and development methods of land or structures subject to protection, including areas at particular risk to landslides (THE ACT, 2003).

\section{General information on the Wieliczka municipality}

Wieliczka is a district town located in the urban agglomeration of Krakow approximately 14 kilometers from the city. The population of the town is just over 20,000 inhabitants. The town of Wieliczka is located in a valley between two ridges of hills that stretch from east to west: from the north of the Bogucice Sands comprising the Wielicko-Gdowska Plateau to the south of the Wieliczka Foothills. It is situated on the border of the Outer Carpathians and the Carpathian Foredeep. Such a position results in the creation of natural landforms associated with the movement of soil and rock, i.e., landslides, in the region of the town and municipality.

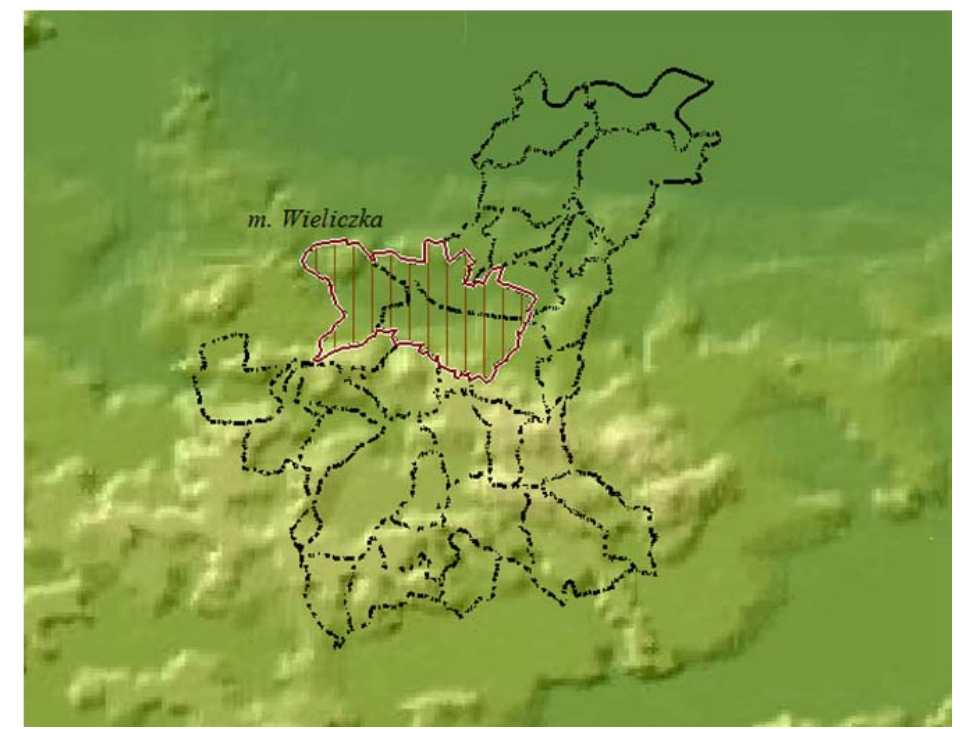

Fig. 1. The town and municipality of Wieliczka against a digital terrain model, Source: own study.

\section{Landslides in the local land use plan in force until 2010}

A landslide area is an area particularly exposed to the phenomenon of sliding rock masses, eluvium or sediments down a slope under the force of gravity. Such areas are of limited use for investment purposes, including residential, industrial or service development. For those areas where landslides are inactive, investments are usually permitted with the imposition of additional conditions associated with them.

From this perspective, a major update of the plan or its total change, resulting in the limitation of the possibilities of developing such sites, is an important issue for owners of these areas. These changes bring about a decline in the value of properties which, under normal market conditions, would not have occurred. The increase or decrease in property values can result from both the change in land-use and the additional restrictions imposed on the land.

This paper examines changes in land use associated with updating areas at risk of landslides. The process has been analyzed based on data from the town of Wieliczka where, in 2008, a comprehensive 
study of landslides was conducted. The results of these studies were introduced to the local land use plan for the town of Wieliczka which was updated accordingly in 2010.

The local land use plan of the municipality, in force until 2010, included landslide areas. It encompassed an area of 79.8 ha, accounting for more than $5.97 \%$ of the total area of the town, i.e., 1,336.9 ha. It is worth noting, however, that the type of landslide was not specified in the plan. Therefore, it was not possible to distinguish which landslides were active and which were not. Figure 2 presents landslides in the local land use plan of 2005. The brown lines mark the boundaries of Wieliczka.

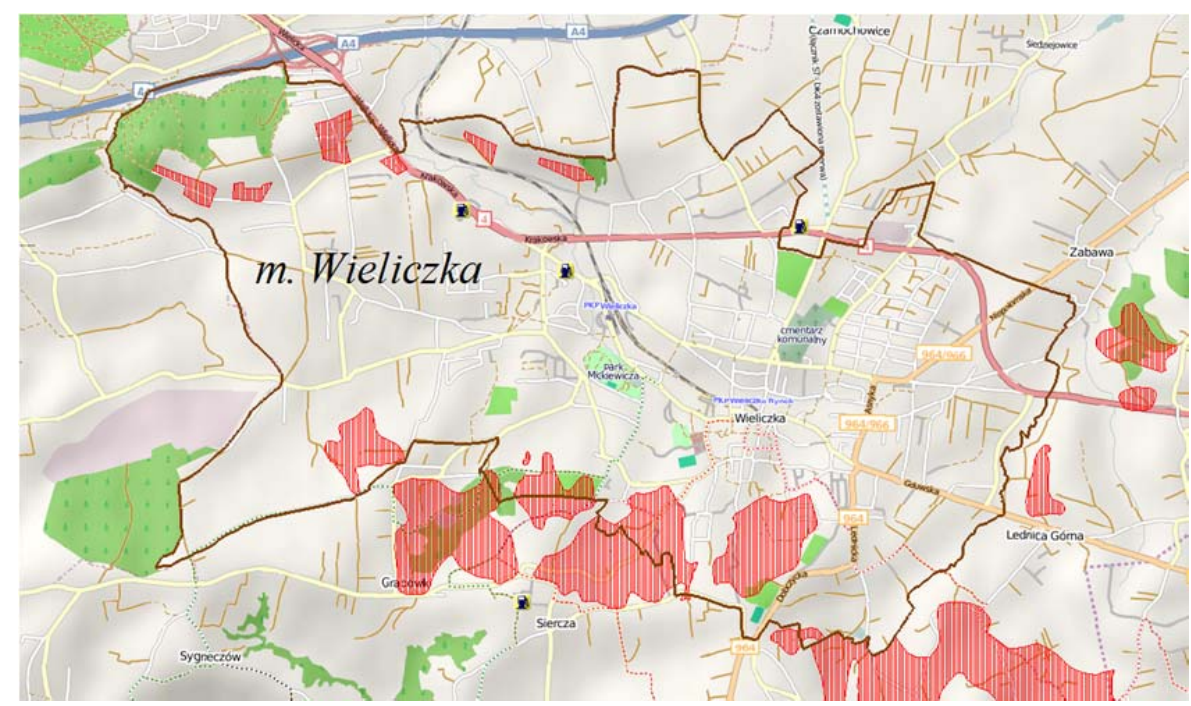

Fig. 2. Landslides in the town of Wieliczka according to the local land use plan of 2005, Source: own study.

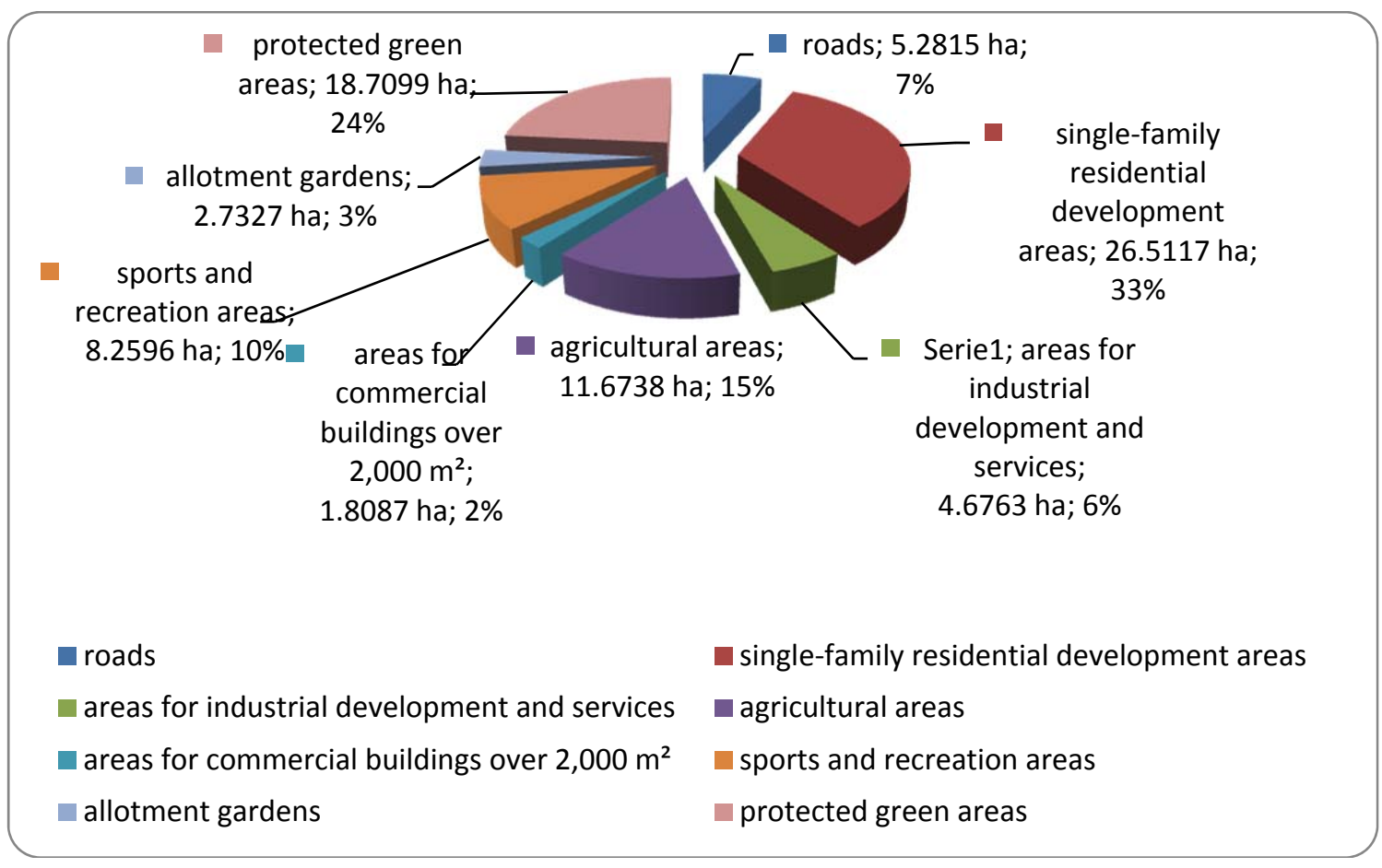

Fig. 3. Uses of landslide areas in the town of Wieliczka according to the local land use plan of 2005, Source: own study.

According to the plan, the landslide areas had various uses. What is interesting, most of the areas exposed to the phenomenon of soil subsidence, i.e., as much as $33 \%$, were marked in the local land use plan as single-family residential development areas, with $24 \%$ intended for use as green areas and 
$15 \%$ for agricultural land. The development of landslide areas was made possible after conducting additional geological research confirming such a possibility.

\section{Changes in landslide areas}

Landslide studies carried out in the municipality of Wieliczka in 2008 were reflected in the new local land use plan adopted in 2010. During the course of the studies, landslide areas were divided into three types, as shown in Figure 3:

- active landslides - red color, solid,

- periodically active landslides - red color, cross-hatching,

- inactive landslides - red color, diagonal hatching.

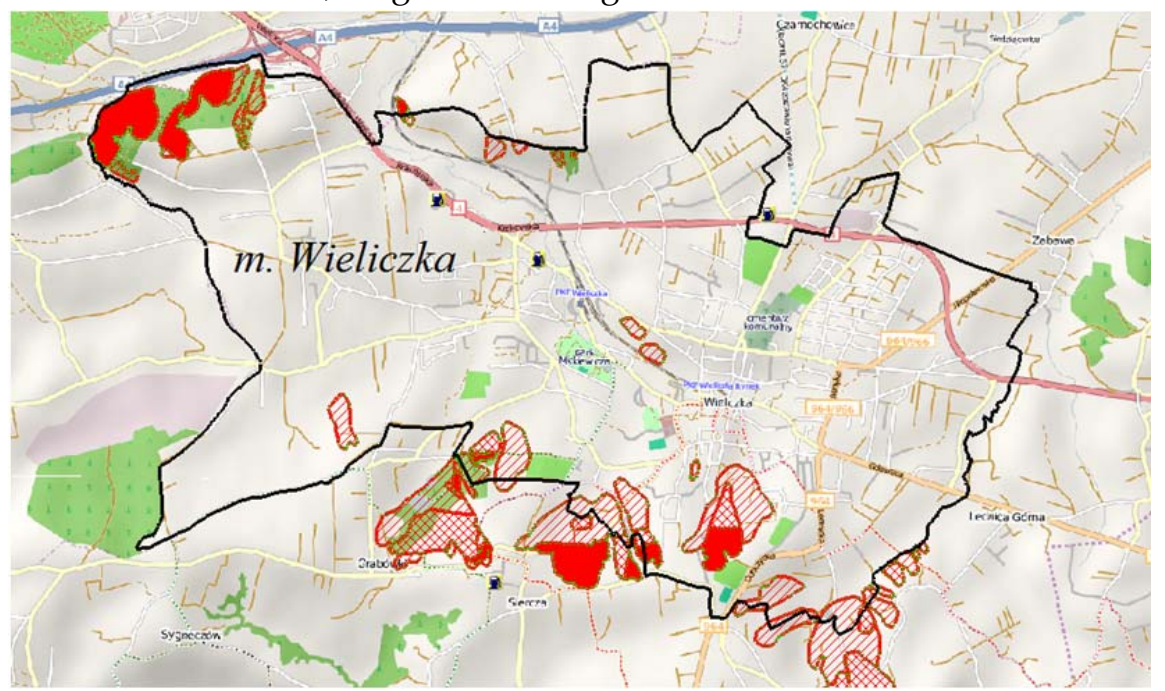

Fig. 4. Landslides in the town of Wieliczka according to the local land use plan of 2010, Source: own study.

The total area of landslides in Wieliczka increased by only 9.6 ha, to a total of 89.4 hectares $(12 \%$ increase). According to the studies of 2008, 28.7 ha (32.1\%) are active landslides, 8.4 ha $(9.4 \%)$ are periodically active landslides, and 52.3 ha $(58.5 \%)$ are inactive landslides. When analyzing the current uses of areas where landslides occur, strong efforts of the authors of the local land use plan which aim to reduce investment processes in areas of active and periodically active landslides, most of which are intended for green areas, are evident. The uses of areas with identified active landslides have been presented in Figure 5.

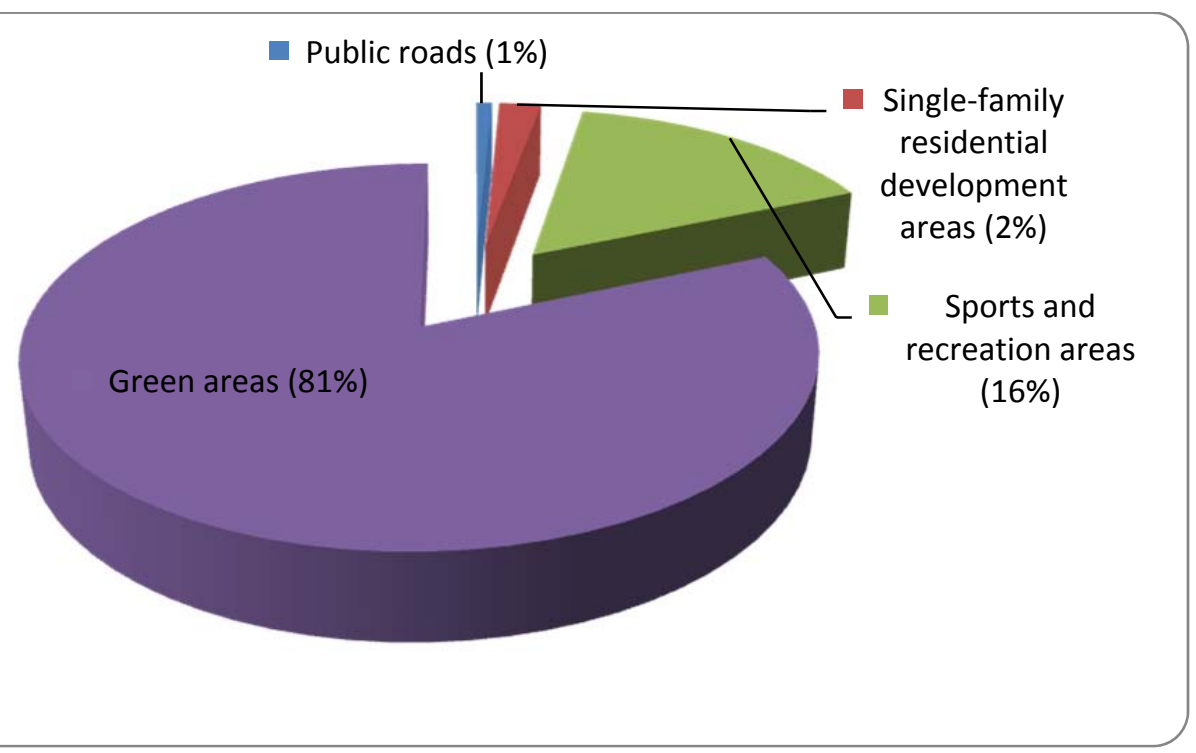

Fig. 5. Use of areas with identified active landslides, Source: own study. 
Areas of possible development, either residential or service, were additionally marked with the letter $\mathrm{O}$, as sites with limited opportunities for development. The use of areas where periodically active and inactive landslides were identified has been presented in Figures 6 and 7, respectively.

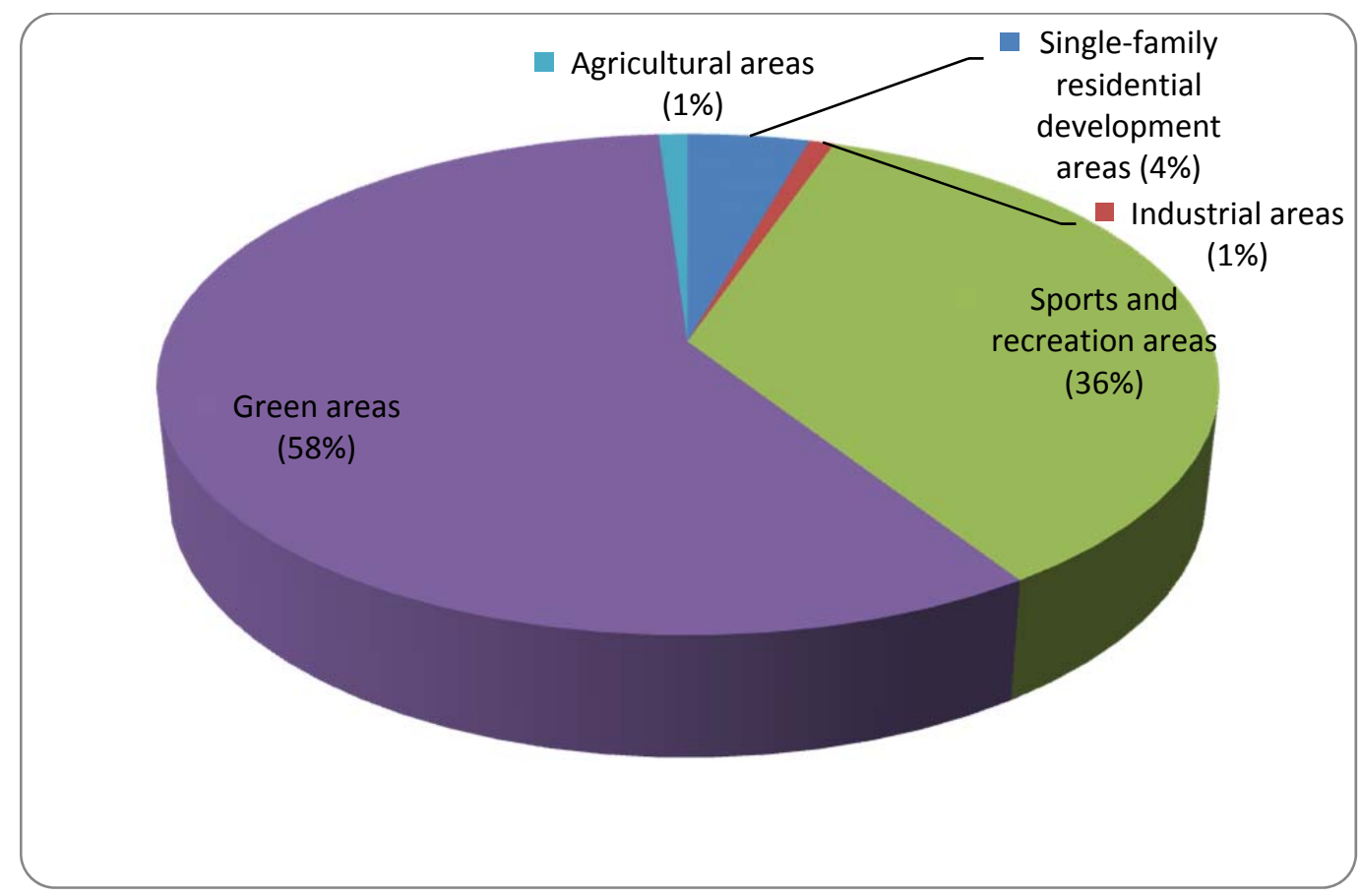

Fig. 6. Use of areas with identified periodically active landslides, Source: own study.

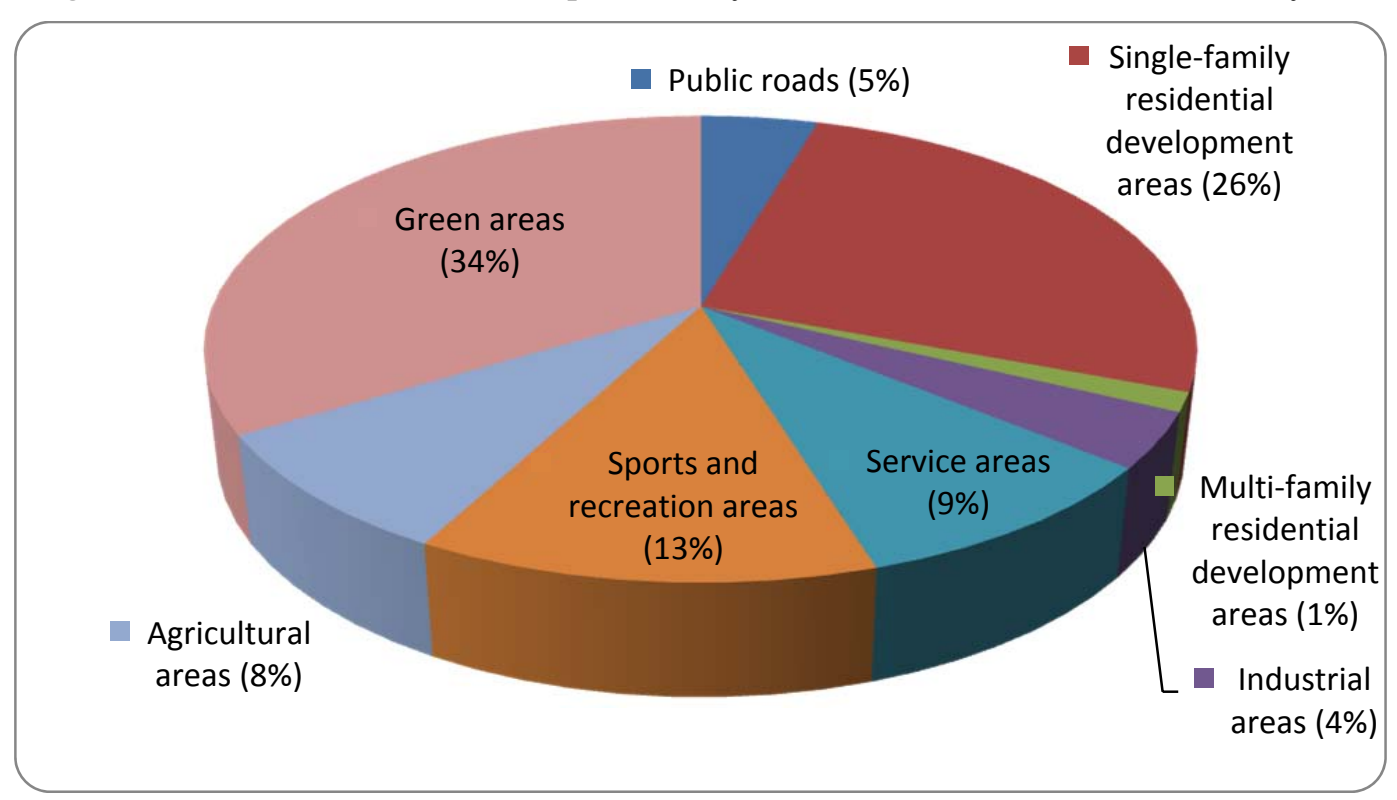

Fig. 7. Use of areas with identified inactive landslides, Source: own study.

The analysis of land-use changes to areas occupied by landslides indicates that 9.7 hectares of the land intended for single-family housing in the plan of 2005 were changed into single-family housing with limited development (MNO). Changes of use into land not suitable for habitation covered an area of only 0.28 ha of landslides. Out of the areas intended for industrial and service development in the local land use plan, 15.5 hectares were changed into industrial or commercial areas with limited development opportunities, and less than 4 ha of such land were excluded from the possibility of use for these purposes, by changing their use to non-commercial and non-industrial. The relatively small surface of areas changed into non-residential or non-commercial and non-industrial use, is probably 
due to the small size of areas where such development could not exist prior to the adoption of the plan. It is difficult to completely change the use of land to non-residential, since residential buildings have already been built in these areas. The aim is rather to limit their further development.

The limited development of land intended for single-family housing in the local land use plan is subject to the following rules:

- new development cannot be located in areas of active and periodically active landslides, including the addition onto and reconstruction of the existing buildings,

- new development in areas of inactive landslides is possible only after drawing up geological and engineering documentation confirming that the proposed investment does not affect the balance of the land and will not activate a landslide,

- it is possible to maintain buildings in areas of active, periodically active and inactive landslides with the recommendation of drawing up appropriate geological and engineering documentation identifying the need for the implementation of security measures.

Similar findings also apply to commercial areas, including sports and recreation areas, as well as to industrial areas with limited development opportunities.

\section{Economic effects of the changes}

The value of terrain which is changed into an area with limited development opportunities as a result of changes in land use resulting from the study of landslides is depreciated. In practice, areas of active and periodically active landslides were excluded from the property market due to the lack of possibility to construct new buildings on it or carry out the reconstruction of or addition onto existing ones. In fact, such a legal regulation makes these areas "doomed" to be gradually transformed from developed into undeveloped agricultural or green areas. After the adoption of the plan, the price of such land plummeted to a level close to that of agricultural and forest land. Naturally, in accordance with the provisions of the Act on Spatial Planning and Development (THE ACT, 2003), the owners of such land are entitled to compensation for the decrease of its value due to the adoption of the plan but, for many of them, this compensation is not adequate to the losses incurred, which are not always tangible.

The areas where inactive landslides were identified, essentially, did not "suffer", except for the additional conditions that were to be met following their development. However, even here the decline in their value can definitely be noticed if in the previous local land use plan the area was not identified as a landslide area. Although the use of such land is possible, it is connected with the extra costs of geological research and costs of improving the security of the buildings.

\section{Summary and conclusions}

Changing the land use in a local land use plan as a result of changing conditions is not a simple procedure, both for the municipality and the owners of that land. On one hand, land use planning within a municipality should take into account the threats to the safety of its inhabitants and their property, as well as identify areas of natural geological hazards; on the other hand, identifying such risks in areas where they have not previously been recognized results in a dramatic decrease in the usefulness of such areas for investments as well as a significant decrease in their value.

The actions taken by a municipality in terms of locating hazards, especially risks of landslides, should make it impossible to carry out investments in areas where there is even a minimal chance of the occurrence of this type of phenomena. Compensation costs associated with the change of land use and decline in its value seem negligible when compared to the possible losses resulting from occurrence of landslides in built-up and inhabited areas.

\section{References}

THE ACT FROM 27 MARCH 2003 ON SPATIAL PLANNING AND MANAGEMENT (DZ. U. 2003 NR 80 POS. 717, WITH LATEST CHANGES). 